\title{
Mixed Mucinous and Invasive Ductal Carcinoma of Male Breast: A Rare Case Report
}

\author{
Kuldeep Ananda Vaidhya ${ }^{1}$ and Sukesh ${ }^{2}$ \\ ${ }^{1,2}$ Associate professor, Department of pathology, Srinivas Institute of Medical Science and \\ Research Centre, Mukka, Mangalore-575021, India. \\ E-mail: vaidyakuldeep@gmail.com
}

Type of the Paper: Medical Case Study.

Type of Review: Peer Reviewed.

Indexed In: OpenAIRE.

DOI: http://dx.doi.org/10.5281/zenodo.809399.

Google Scholar Citation: IJHSP

\section{How to Cite this Paper:}

Vaidhya, Kuldeep Ananda, Sukesh. (2017). Mixed Mucinous and Invasive Ductal Carcinoma of Male Breast: A Rare Case Report. International Journal of Health Sciences and Pharmacy (IJHSP), 2(1), 1-4.

DOI: http://dx.doi.org/10.5281/zenodo.809399

International Journal of Health Sciences and Pharmacy (IJHSP)

A Refereed International Journal of Srinivas University, India.

(C) With Authors

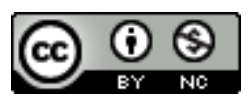

This work is licensed under a Creative Commons Attribution-Non Commercial 4.0 International License subject to proper citation to the publication source of the work.

Disclaimer: The scholarly papers as reviewed and published by the Srinivas Publications (S.P.), India are the views and opinions of their respective authors and are not the views or opinions of the SP. The SP disclaims of any harm or loss caused due to the published content to any party. 


\title{
Mixed Mucinous and Invasive Ductal Carcinoma of Male Breast: A Rare Case Report
}

\author{
Kuldeep Ananda Vaidhya ${ }^{1}$ and Sukesh ${ }^{2}$ \\ ${ }^{1,2}$ Associate professor, Department of pathology, Srinivas Institute of Medical Science and \\ Research Centre, Mukka, Mangalore.575021 \\ E-mail: vaidyakuldeep@gmail.com
}

\begin{abstract}
Male breast carcinoma is a rare entity. Here, we present a case of mixed mucinous carcinoma i.e. composite mucinous carcinoma with infiltrating ductal carcinoma component in a 55 year old man. Patient clinically presented with a lump in his right breast. Histopathological examination of the breast mass showed tumor cells arranged in nests, cords, cribriform pattern in a mucinous stroma and a part of tumor was showing features of infiltrating ductal carcinoma with desmoplastic stroma.
\end{abstract}

Keywords: Mucinous carcinoma, Invasive ductal carcinoma, Breast, Histopathology.

\section{INTRODUCTION :}

Male breast carcinoma is a rare entity, representing less than $1 \%$ of all breast cancer cases [1]. Mucinous carcinoma is an extremely rare neoplasm; In men it accounts for less than $2 \%$ of breast carcinomas[2]. Composite male breast malignancy comprising of mucinous and invasive ductal carcinoma components is also a rare entity and described in only few literatures.

\section{CASE REPORT :}

A 55 year old man came with the history of a palpable lump in his right breast since 6 months associated with mild local discomfort since 2 weeks. There was no history of nipple discharge. There was no other relevant medical history known to be associated with gynecomastia. On physical examination, there was a firm lumpover the chest wall just below the areola, soft to firm in consistency, measuring around $3.5 \times 3 \mathrm{~cm}$. Axillary lymph nodes were not palpable and no visible overlying skin or nipple changes. Breast ultrasonography showed a circumscribed isoechoic solid mass situated below the nipple and areola. Breast FNA yielded scant greyish white material, stained smears revealed atypical ductal cells in clusters and sheets, in a mucoid background, based on these findings, cytological impression of malignant breast lesion was given and advised histopathological examination. Modified radical mastectomy was done and sent in formalin for histopathological examination.

Grossly tumor was well demarcated, soft to firm in consistency with partly grey white and partly mucoid in nature with foci of haemorrhage [Fig.1]. Tumor was situated $2 \mathrm{~mm}$ deep to skin and $1 \mathrm{~mm}$ above the deep resected margin. No lymph nodes were isolated. Sections from the mass showed tumor cells arranged in nests, cords, cribriform pattern in a mucinous stroma [Fig. 2]. Cells were showing anisonucleosis, having moderate eosinophilic cytoplasm, vesicular nuclei, occasional mitosis. Part of tumor was showing tumor cells in nests, cords, sheets and trabecular pattern infiltrating the desmoplastic stroma with sparse lymphocytic aggregation [Fig. 3]. No evidence of lymphovascular tumor emboli or perineural invasion of tumor cells. Section from nipple, areola was unremarkable and free from tumor. A final diagnosis of mixed mucinous carcinoma of breast - 50\% mucinous component with $50 \%$ invasive ductal carcinoma component was given.

\section{DISCUSSION :}

Invasive ductal carcinoma of no special type is the most common type of male breast 
carcinoma, accounting for $~ 90 \%[3]$. Major genetic factors associated with an increased risk of men breast cancer have been identified including BRCA2 mutations, Klinefelter syndrome and a family history of breast carcinoma. Epidemiologic risk factors for male breast cancer include disorders relating to hormonal imbalances such as obesity, testicular disorders and radiation exposure. Suspected epidemiologic risk factors include prostate cancer, gynecomastia, dietary factors and alcohol intake [4] in our case apart from history of alcohol consumption, no other risk factors were identified.

Mucinous carcinoma of the male, also called as colloid or gelatinous carcinoma is an extremely rare histological subtype. It is a variety of breast carcinoma characterized by the production of abundant mucin [5]. The clinical features of pure mucinous carcinoma are nonspecific. The typical clinical appearance consists in a palpable lump. The lesion is remarkably well delimited and sometimes fluctuant on physical examination [6], in this present case mass was well circumscribed with soft to firm in consistency. Mucinous carcinoma is histopathologically sub classified into pure and mixed types. The pure form is defined as a lesion with a mucinous carcinoma component of $>90 \%$ of the tumor; the mixed type is defined as having mucinous and conventional invasive ductal carcinoma components [3]. In the present case, a diagnosis of mixed mucinous carcinoma was made since there was a significant conventional invasive ductal carcinoma component present. Sections in our case were subjected to mucicarmine stain and highlighted the mucinous component. Pure mucinous carcinomas are further sub-classified as type A, hypocellular and type B, hypercellular type. They are frequently associated with lower rates of recurrence. Mixed type behaves as aggressively as isolated invasive carcinoma [7-8] and should be treated in the same manner as an infiltrating duct carcinoma of breast [9]. The treatment is also similar to female breast cancer, consists of local clearance by modified radical mastectomy with axillary lymph node dissection. There is similar role for adjuvant therapy in male breast cancer as in female breast cancers [10].

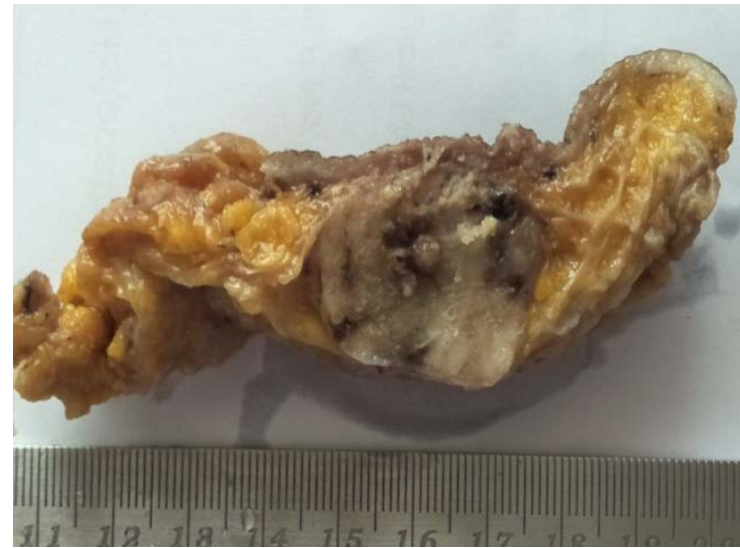

Fig. 1: Cut section showed a well circumscribed mass having grey white and mucoid areas with areas of haemorrhage.

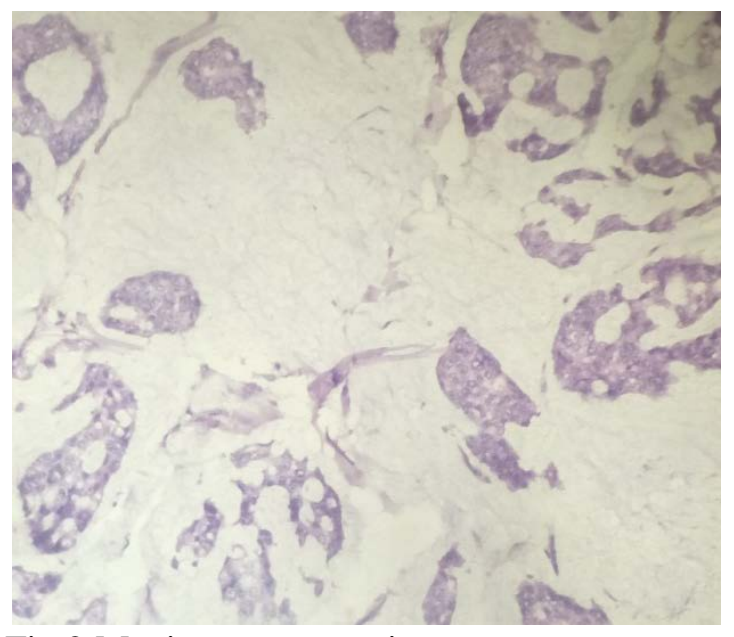

Fig.2:Mucinous carcinoma component showing neoplastic cells forming acini, clusters, embedded in a pool of mucin.

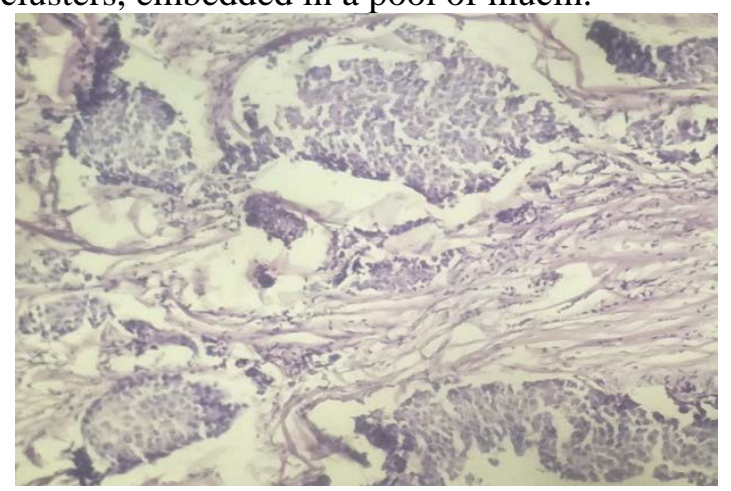

Fig. 3:Invasive ductal carcinoma component showing infiltrating tumor cells in nests and cords with desmoplastic stroma.

\section{CONCLUSION :}

Composite male breast malignancy comprising of mucinous and invasive ductal carcinoma components is a rare entity. A mixed mucinous carcinoma should be treated in the same 
manner as an infiltrating ductal carcinoma. Awareness of this entity amongst surgeons and pathologist is required for early correct diagnosis and proper treatment.

\section{REFERENCES :}

[1] Siegel R, Naishadham D, Jemal A. Cancer statistics, 2012. CA Cancer J Clin 2012; 62: 10-29.

[2] Peschos D, Tsanou E, Dallas P, Charalabopoulos K, Kanaris C, Batistatou A. Mucinous breast carcinoma presenting as Paget's disease of the nipple in a man: A case report. Diagn Pathol 2008;3:42.

[3] Bussolati G and Sapino A: Mucinous carcinoma and carcinomas with signet-ring cell differentiation. In: World Health Organization Classification of Tumours of the Breast. Lakhani SR, Ellis IO, Schnitt SJ, Tan PH and van de Vijver MJ (eds). IARC Press, Lyon, France, 2012:60-1.

[4] Ottini L, Palli D, Rizzo S, Federico M, Bazan V, Russo A. Male breast cancer. Crit Rev Oncol Hematol. 2010 Feb; 73(2):141-55.

[5] Kavalakat A.J, Covilakam R.K, Culas T.B. Secretory carcinoma of breast in a 17year old male. World J Surg Oncol. 2004; 2:17.

[6] Dragoumis D.M, Assimaki A.S, Tsiftsoglou A.P. Pure mucinous carcinoma with axillary lymph node metastasis in a male breast. Breast Cancer. 2009;10.

[7] Bae S.Y, Choi M.Y, Lee J.E, Nam S.J, Yang J.H. Mucinous Carcinoma of the Breast in Comparison with Invasive Ductal Carcinoma: Clinicopathologic Characteristics and Prognosis. J Breast Cancer. 2011;14(4):308-13.

[8] Kashiwagi S, Onoda N, Asano Y, Kawajiri $\mathrm{H}$, Takashima T, Ohsawa M, et al.Clinical significance of the sub-classification of 71 cases mucinous breast carcinoma. Springerplus. 2013;2:481-86.

[9]Anan K, Mitsuyama S, Tamae K, Nishihara K, Iwashita T, Abe Y, Ihara T, Nakahara S, Katsumoto F, Toyoshima S. Pathological features of mucinous carcinoma of the breast are favourable for breast-conserving therapy. EJSO 2001; 27: 459-63

[10] Giordano S.H, Buzdar A.U, Hortobagyi G.N. Breast cancer in men. Ann Intern Med. 2002;137:678-87. 